\title{
A Personal Perspective on Short Courses
}

Editor's Note: $M R S$ frequently receives feedback from its members on its programs and services. The following testimonial in particular provides some insight into the benefits of short courses in continuing education.

One of the biggest problems facing U.S. industry is the obsolete technical professional, be that person a scientist, engineer, or technician. Once you are out of school, it gets increasingly difficult to become educated in new areas or even to stay current in old ones. Yet, if you and your company are to remain competitive, it is absolutely essential that the educational process continue. Science and technology do not stand still, nor do the business opportunities and pitfalls based on them.

Of course most of us try to learn and stay current by reading articles and going to conferences. This helps, but it is not enough. Unless you are already very familiar with a subject, it is almost impossible to sort through the plethora of published articles and put the information into some sort of coherent order or understanding. Attendance at conferences allows you to ask questions of colleagues, but there is never enough time to make all the inquiries you need, assuming you can think of them at the time. Also, this piecemeal gathering of information is no more effective at giving an overall picture of a subject or area than reading articles.

What is the solution? Go back to school? Aside from the fact that very few of us have the time or inclination for that, there exist few standard university courses that cover the cutting edge technologies. The ones that do exist are usually not very accessible to working professionals due to either scheduling or geography.

Presently, the best answer to all of this is to attend short courses. In a very short time (one, two, or at most three days) you can come up to speed in a subject. Attending a short course has a number of benefits. You are removed from the distractions of work, and focused on a single topic. You are in a setting that encourages asking questions, even ones of a very basic nature. And, perhaps most important, you are being instructed by an expert who has already acted as a "filter" for the information overload in the published literature, and who can provide you with a bibliography of truly important references.

My own experience is mostly with MRS short courses. I have attended several at the MRS meetings, have suggested a new course which was implemented, and have begun a program at United Technologies Research Center (UTRC) of bringing short courses on-site. The MRS program of short courses is probably one of the largest offered by any society, and covers a wide range of materials-related topics. In addition to a large variety of topics, there are courses with a variety of "depths," ranging from rather general overviews of an area (e.g., Optoelectronic Materials, Processes, and Devices) to in-depth instruction on a specific technical topic (e.g., Deep Level Transient Spectroscopy). My experience with the MRS short course program has been uniformly good, and 1 consider the opportunity for continuing education that this program provides to be one of the most important functions of this society. (No, they didn't pay me to say this.)

Since I mentioned on-site short courses above, I would like to discuss them versus courses given at meetings. Many of the benefits of on-site courses are to the group or organization, rather than the individual. One advantage is that if enough people attend, the cost per-person can come down tremendously. The breakeven point depends on how far you would have to travel to reach a short course being conducted during an MRS meeting. For UTRC, travel to Boston for the MRS Fall Meeting is not very expensive since we are in Connecticut, but the break-even point is still only about seven attendees. Naturally if you are further away, your institution's break-even point will be even lower. If you can fill a class (generally a maximum of 25), the cost per person for a one-day course is less than $\$ 200$. I consider that to be one of the best educational bargains around. The down side is that your management has to be convinced to spend a few thousand dollars at one shot for education. Depending on how progressive they are on continuing education, this could be a big hurdle.

Another advantage of an on-site short course is that people will attend who normally couldn't or wouldn't. An example is technicians, who are generally not encouraged to attend meetings or take short courses. Whether technician attendance at an on-site course is appropriate will depend on the depth of the course, but there are many cases where they derive great benefit. By eliminating travel, you also attract the scientists and engineers who feel they do not have the time to travel to a meeting, or who are (dare I say it?) just a little bit lazy.

A possible disadvantage to having a course on-site is that some of the attendees think of themselves as still being at the office, and can end up missing large parts of the class when they have to "fight fires." If choices in the attendee list had to be made due to great interest in the course, these half-participants are taking the place of someone else who would have derived greater benefit from being present the whole time.

One aspect of on-site courses that can be viewed in two different lights is that you are attending this course with only your co-workers. This can serve to stimulate discussion on problems of mutual interest and help you find out what the person down the hall (or even in the next office) is doing. On the other hand, attending a course at a meeting puts you in touch with attendees from different organizations. This is a good chance to expand your contacts with colleagues of different backgrounds or with different viewpoints but with whom you have something in common (since you are all attending the same courses.) Furthermore, attending a short course at a meeting gives you the opportunity to attend some of the technical sessions or other activities, such as equipment shows.

The decision whether to take a course at a meeting or to bring it on site is based on a number of factors. Cost effectiveness is probably the single biggest consideration, based on the number of likely attendees at your workplace. Other factors include how receptive management is to the idea, and whether you were planning on attending that particular meeting anyway. My own motivations for starting to bring courses on-site were part altruistic and part selfish: I felt it would do my organization some good, and it was a way for me to take more courses than I could otherwise. The healthiest policy from the view. point of both individuals and organizations is probably a mix of both on-site and off-site courses.

I'll end on this note: whether it's on or off-site, take a short course. Even if it's on a peripheral subject, or a review of a topic with which you are already familiar. It's good for your sanity to get back in a learning mode once in a while.

Robert N. Sacks

United Technologies Research Center Hartford, CT 06108 